\title{
Not practicing what we teach? The case for healthy food and drinks at health training events
}

\author{
Colin Pfaff ${ }^{1,2}$, Gift Malamula ${ }^{1}$, Joep J van Oosterhout ${ }^{1,3}$ \\ 1. Dignitas International, Zomba, Malawi \\ 2. University of Malawi College of Medicine, Family Medicine Department, Blantyre, Malawi \\ 3. University of Malawi College of Medicine, Department of Medicine, Blantyre, Malawi
}

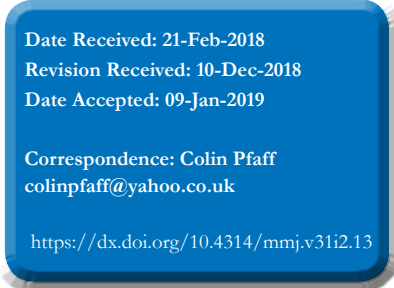

Non communicable diseases (NCDs) are on the rise in all countries in Africa, including Malawi ${ }^{1}$ and will soon overtake infectious disease as the leading cause of death if appropriate interventions are not implemented in many African countries ${ }^{2}$. Health care workers in Sub Saharan Africa are not immune to these conditions. NCDs, especially hypertension and diabetes are largely driven by lifestyle related factors including diet and recommendations regarding life style change form an important part of health education by primary care clinicians ${ }^{3}$ and at NCD clinics. Changes in both the local and global food environment, with increased availability of cheap energy-dense food have contributed to these lifestyle and diet changes ${ }^{4}$. In this regard medical and research institutions in Malawi may be accused of not practicing what they advocate - a diet low in sugar and fat and high in fruit and vegetables 5 . In 2016 Dignitas International, a medical and research organization dedicated to improving health care for people facing a high burden of disease and unequal access to services trained over 4800 health care workers in diagnosing HIV, TB, hypertension and diabetes. As is common practice in Malawi, all of these trainings provide twice daily soft drinks, cakes and fried snacks to the participants. It is estimated that during this period, we supplied approximately 40000 bottles of soft drinks to Ministry of Health officials and other staff, thus contradicting in practice the messaging about the importance of healthy diets and lifestyle in NCD prevention.

In 2018, the facilitation of a training seminar for diabetic expert clients forced us to reconsider our approach. Diabetic expert clients are patients who have diabetes and who are trained to conduct peer-to-peer education at diabetes clinics. Partnering with a local entrepreneur in Zomba, a city in Southern Malawi, who took the initiative to develop diabeticfriendly snacks, we piloted this initiative to supply water, tea and snacks made from healthy ingredients during this threeday training. The snacks consisted of cakes and other snacks that were made with low fat and sugar free ingredients, all sourced locally. Participants in this training were enthusiastic about this. They expressed that in other circumstances they had been forced to make unhealthy compromises. We would like to encourage other organisations and institutions in Malawi to join our approach by providing healthy snacks during training events and avoiding the provision of snacks and drinks with high fat and sugar content. In our experience this initiative was not more expensive than usual provisions, (costing Mk 3200 per person) was not hard to arrange and supported local business. It communicated a powerful message both to the participants, to our staff and to the staff of the training venue. If all NGOs and other organisations in Malawi would provide healthy snacks without soft drinks during training meetings, we may send out as strong a message as those conveyed during the training sessions themselves. We hope that this letter may provoke some healthy debate as to whether this may be possible.

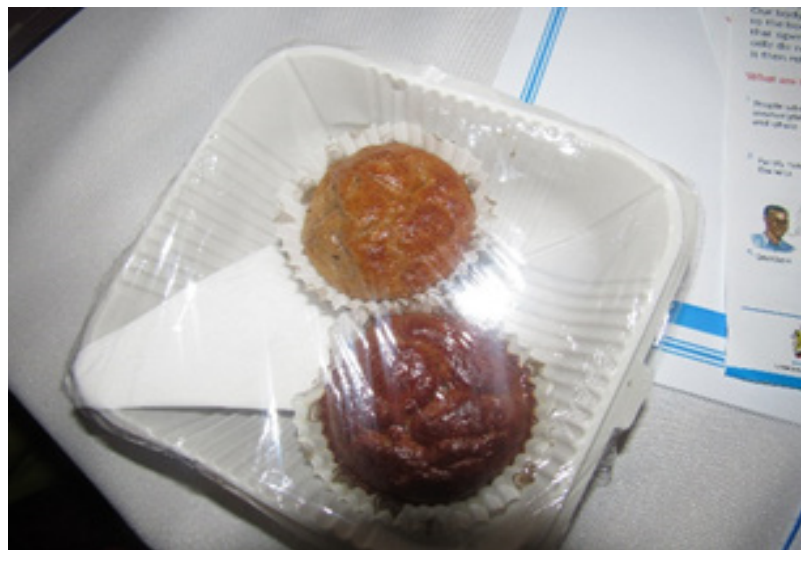

Figure: healthy snack at Diabetes project training

\section{References}

1. Price AJ, Crampin AC, Amberbir A, Kayuni-Chihana N, Musicha C, Tafatatha $\mathrm{T}$ et al. Prevalence of obesity, hypertension, and diabetes, and cascade of care in sub-Saharan Africa: a cross-sectional, populationbased study in rural and urban Malawi. Lancet Diabetes Endocrinol. 2018; 6(3): 208-222. doi: 10.1016/S2213-8587(17)30432-1

2. Mathers CD, Loncar D. Projections of global mortality and burden of disease from 2002 to 2030. PLoS Med. 2006; 3 (11): e442. doi. org/10.1371/journal.pmed.0030442

3. Malan Z, Mash R, Everett-Murphy K. Qualitative evaluation of primary care providers experiences of a training programme to offer brief behaviour change counselling on risk factors for non-communicable diseases in South Africa. BMC Fam Pract. 2015; 16:101. doi: 10.1186/ s12875-015-0318-6.

4. Swinburn B A, Sacks G, Hall KD, McPherson K, Finegood D, Moodey $\mathrm{M}$ et al. The global obesity pandemic: shaped by global drivers and local environments. Lancet. 2011; 378: 804-14. doi.org/10.1016/ S0140-6736(11)60813-1

5. World Health Organisation. Global action plan for the prevention and control of non-communicable diseases 2013-2020. Geneva: WHO; 2013 